\title{
PARA ALÉM DA ANÁLISE EPISTEMOLÓGICA: CRÍTICA DA PRODUÇÃO DO CONHECIMENTO À LUZ DAS DETERMINANTES DO MODO DE PRODUÇÃO ${ }^{i}$
}

Elza Margarida de Mendonça Peixoto ${ }^{\text {ii }}$

\section{RESUMO}

Vemos avançar os estudos que buscam analisar epistemologicamente a produção do conhecimento em Educação Física, Esportes e Lazer, objetivando: (a) identificar as áreas do conhecimento que têm influenciado a educação física; (b) identificar a viabilidade de sua configuração como um campo científico; (c) identificar as principais temáticas que vêm sendo abordadas na área; (d) identificar e analisar a consistência teórico-metodológica das pesquisas em busca da percepção de seu grau de cientificidade e de sua conexão com as teorias do conhecimento. Destacando a relevância destas pesquisas para a identificação da direção política da produção do conhecimento, defendemos que as análises da produção do conhecimento devem ultrapassar as fronteiras das análises epistemológicas em busca de explicação sobre os nexos entre a produção do conhecimento e o estágio de desenvolvimento das forças produtivas e das relações de produção próprias do modo de produção capitalista. Trata-se de precisar que a produção do conhecimento decorre da correlação de forças entre as classes em disputa (relações de produção) pelo controle e direção do desenvolvimento das forças produtivas. Toda e qualquer produção do conhecimento se faz na luta de classes entre capital e trabalho, classes com interesses contraditórios e divergentes, sendo fundamental avançar nas explicações que expõem os nexos entre a produção do conhecimento e os interesses em conflito que a subjazem, precisando estes interesses contraditórios e suas bases econômicas correspondentes. Este artigo conclama aos pesquisadores a tomarem modo de produção como categoria chave para a explicação dos nexos da produção do conhecimento com a economia política.

Palavras-chaves: Modo de Produção, Trabalho, Produção do Conhecimento, Ideologia.

\section{BESIDES OF EPISTEMOLOGICAL ANALYSIS: CRITICAL OF KNOWLEDGE PRODUCTION IN THE LIGHT OF DETERMINING THE MODE OF PRODUCTION}

\section{ABSTRACT}

We see to advance studies that seek analyze epistemologically the knowledge production about Physical Education, Sports and Leisure, aiming: (a) to identify the knowledge areas that have influenced physical education; (b) to identify the viability of their configuration as a scientific field; (c) to identify the main themes that have been addressed in the area; (d) to identify and analyze the theoretical and methodological consistency of the researches in search of their scientific degree and their connection with the knowledge theories. Emphasizing the relevance of these researches to the identification of political direction of the knowledge production, we defend that the analysis of knowledge production must exceed the boundaries of the epistemological analysis in search of explanation about the connections between the knowledge production and the development stage of the productive forces and of the production relations of the capitalist mode of production. It's necessary to determine that the knowledge production derives from correlation of forces between social classes in dispute (production relations) by the control and direction of productive forces development. All and any knowledge production is done in class struggle between capital and work, social classes with contradictory and divergent interests, being essential to advance in the explanations that expose the connections between the knowledge production and the conflicting interests that underlies itself, determining these contradictories interests and their corresponding economic bases. This article urges the researchers to take production mode as key category to the explanation of the connections of knowledge production with the political economy.

Keywords: Mode of Production, Work, Knowledge Production, Ideology. 


\section{Introdução}

Apoiados no esquema paradigmático aprimorado por Gamboa (1986, 1987), estudos vêm sendo feitos com a finalidade de pesquisar as pesquisas desenvolvidas em Programas de Pós-Graduação no Brasil no âmbito da Educação Física, Esportes e Lazer. Pioneiros entre estes trabalhos são a Dissertação Mestrado em educação física no Brasil: pesquisando suas pesquisas (1990), e a Tese Pesquisa em educação física: determinações históricas e implicações epistemológicas (1997), ambas desenvolvidas por Silva. Posteriormente, encontramos a Dissertação Lazer, Trabalho e Educação: pressupostos ontológicos dos estudos do lazer no Brasil (2002) e a Tese Pressupostos ontológicos da produção do conhecimento do lazer no Brasil - 1972 a 2008: realidade e possibilidades na pósgraduação e graduação em educação física (2009), desenvolvidas por Sá. Entre estes dois trabalhos, Chaves desenvolve a Tese de Pós-Doutorado A produção do conhecimento em educação física nos Estados do Nordeste (Alagoas, Bahia, Pernambuco e Sergipe), 19822004: balanço e perspectivas (2005) e Albuquerque desenvolve a Dissertação de Mestrado A produção de pesquisas em educação física, esporte e lazer com a temática escola no nordeste brasileiro [1982-2004]: mediações e possibilidades da educação para além do capital (2007). Há em comum entre estes trabalhos o esforço de precisar os referenciais teóricos que estão influenciando e determinando o desenvolvimento da produção do conhecimento em educação física, esportes e lazer no Brasil. Configurados como balanços da produção do conhecimento, os estudos apresentados até aqui explicitam o predomínio do paradigma empírico-analítico na produção das pesquisas, com progressiva expansão das abordagens fenomenológico-hermenêuticas e crítico-dialéticas, movimento que se passa entre 1972 e 2009, com especial destaque para a região Nordeste do país, abordada nos estudos de Chaves (2005), Albuquerque (2007) e Sá (2009).

Recentemente, Ávila, na Tese de Doutorado A pós-graduação em educação física e as tendências na produção do conhecimento: o debate entre realismo e anti-realismo (2008), destaca que o terreno epistemológico da produção do conhecimento se alargou, abarcando perspectivas que não podem ser enquadradas na matriz paradigmática adotada nas análises dominantes na área, uma vez que $47 \%$ das teses "não se encaixam no quadro analítico que tem sido referência para a compreensão epistemológica dessa área de estudo", evidenciando-se que há limites nas análises epistemológicas no que toca à apreensão do debate realismo/anti-realismo (Ávila, 2008). No conjunto destes estudos evidencia-se o debate sobre as implicações decorrentes da direção política da produção do conhecimento quando subordinada às referências realista/anti-realistas (Ávila, 2008), materialista/idealista (Sá, 2009), empírico-analíticas/ fenomenológico-hermenêuticas/ crítico-dialéticas (Chaves, 2005; Albuquerque, 2007 e Sá, 2009).

Decorrendo dos avanços na análise da relação da produção do conhecimento com a economia política, explicita-se - a partir dos estudos desenvolvidos por Lombardi, recentemente sistematizados na Tese de Livre Docência Reflexões sobre educação e ensino na obra de Marx e Engels (2009), e da Tese de Doutorado Estudos do lazer no Brasil: apropriação da obra de Marx e Engels (2007), produzida por Peixoto sob a orientação de Lombardi - a preocupação com a explicação das Concepções predominantes na produção do conhecimento à luz do estágio de desenvolvimento das forças produtivas e das relações de produção próprias do capitalismo como modo de produção da existência hegemônico a partir do final do século XX.

Nesta exposição, recuperamos o debate, defendendo que a análise da produção do conhecimento deve ultrapassar os limites das análises epistemológicas em busca da 
explicação dos nexos entre a produção do conhecimento e o estágio de desenvolvimento do modo de produção capitalista na formação social brasileira.

\section{A história da pergunta}

[...] ao combaterem as fraseologias deste mundo, não combatem de modo algum o mundo real existente [...]. A nenhum destes filósofos ocorreu a ideia de perguntar sobre a conexão entre a filosofia alemã e a realidade alemã, sobre a conexão de sua crítica com seu próprio meio material

(MARX, K., ENGELS, F., 2007, p. 84).

Entre 2003 e 2007, desenvolveu-se pesquisa que tratou do Levantamento, catalogação e análise da produção do conhecimento referente aos estudos do lazer no Brasil pretendendo levantar, catalogar, compilar, analisar e produzir sínteses explicativas sobre o modo como a obra de Marx e Engels vinha sendo apropriada para explicar a problemática do lazer. A partir desta pesquisa, produziu-se a tese de doutorado "Estudos do Lazer no Brasil: apropriação da obra de Marx e Engels".

Este estudo da produção do conhecimento referente aos estudos do lazer no Brasil não esteve focado em uma análise epistemológica em sentido stricto, mas em explicar as condições históricas que permitiram o desenvolvimento da preocupação com a problemática do lazer, que levou a esta produção do conhecimento e aos referenciais teóricos nela privilegiados ou negados. Desejava-se conhecer a realidade que explicava esta produção.

Ora, a pergunta sobre a realidade que explicava a produção do conhecimento referente aos estudos do lazer no Brasil não surgiu da cabeça, espontaneamente. Antes, decorreu de inquietações trazidas pelo estudo da abordagem brasileira da problemática do lazer associado ao esforço de explica-la na perspectiva da concepção materialista e dialética da história (PEIXOTO, 2007a).

Inquietavam-nos os esforços dos estudiosos do lazer brasileiros em reconhecer/estabelecer um "campo" destacado de práticas, políticas, formação e produção do conhecimento que, supostamente, se distinguia e se destacava de todos os outros pela especificidade de referir-se ao "querer" e ao "fazer" em um instante da existência que se apresentava simultaneamente (ou isoladamente) como um "tempo", uma "atividade" e uma "atitude" destacados das chamadas "demais esferas da vida" (PEIXOTO, 2007a).

Uma profusão significativa de estudos pretendeu esgotar a problemática estabelecendo relações empiristas, que, recorrendo ao uso de conjunções aditivas e adversativas, simultaneamente, com a finalidade de atribuir valor equitativo aos termos da relação e com a finalidade de estabelecer entre elas relação de oposição, discutiam o lazer em relação ao trabalho, à educação, à humanização, ao esporte, à educação física, à recreação, à empresa, à sociedade, à escola entre outros (PEIXOTO, 2007a; PEIXOTO, 2007c; GUILHERME, MANCONI e PEIXOTO, 2010).

No processo de teorizar estas relações ou oposições, sem qualquer disciplina teórica ${ }^{\text {iii }}$, a abordagem empirista do objeto estabelecia-se a partir da incorporação, pela especulação, de valores/sentidos/significados considerados próprios da essência do lazer confrontados com os valores/sentidos/significados do não lazer, conformados como "antilazer". A especulação movimentava-se, então, ao encontro de um estado puro essencial que definia o ser e o não ser do lazer, que, de objeto na existência, passa a ser $o$ Ser da existência a ser buscado pelos praticantes e animadores. À luz deste estado puro idealizado, na superioridade da perfeição de um objeto artificialmente construído pela especulação, os arautos do Lazer (o Ser espelho ao qual todos devem almejar obter semelhança), decidiam 
quais os referenciais que possuíam a possibilidade de espelhar Sua realidade perfeita. Neste processo, o marxismo, e, em especial, a obra de Marx e Engels foram apropriados, torcidos, distorcidos e invertidos (PEIXOTO, 2007a; PEIXOTO, 2008d).

Para compreender este processo, tornou-se necessário, simultaneamente, (1) realizar a análise da produção do conhecimento referente aos estudos do lazer no Brasil, e, nela, a análise da apropriação da obra de Marx e Engels (PEIXOTO, 2007a); (2) estudar cronologicamente $^{\mathrm{iv}}$ o processo de desenvolvimento da concepção materialista e dialética da história com a finalidade de, com disciplina teórica, compreender o objeto e a produção do conhecimento sobre o objeto, reconhecendo as formulações mais avançadas para a explicação da problemática do lazer (PEIXOTO, 2007a). Foi no movimento de conhecer o que já era conhecido que pudemos conhecer o que ainda não era conhecido (SAVIANI, 1987, p. 51): as raízes da veemente negação, pelos estudiosos do lazer, do marxismo com referencial possível/viável para o estudo da problemática do lazer no Brasil.

Se a inquietação - expressão de uma necessidade objetiva que se apresentava subjetivamente (SAVIANI, 2007, p. 11-29) - já havia sido conformada em problema científico, tratava-se, então, de delimitar, com disciplina teórica, o caminho para alcançar a resposta à pergunta científica.

A disciplina teórica para a produção da resposta à pergunta:

É sabido que as investigações marxianas se alçarão a novo patamar nos anos cinquenta; na segunda metade desta década, Marx efetuará as suas mais decisivas descobertas. Ora, sobre que fundamentos se efetivam estas descobertas? Sobre o fundamento da mais central das determinações de Marx, aquela que já se apresenta na Miséria da Filosofia: a determinação de que as instâncias constitutivas da sociedade se articulam numa totalidade concreta e são postas geneticamente pelo primado ontológico das relações econômicas. Não se trata, como sempre quis o marxismo vulgar, de reduzir a teoria social de Marx a uma teoria fatorialista, com o primado do "econômico"; nada disto: o primado ontológico da economia, que funda a teoria social moderna, descoberto por Marx, opera no interior de uma estrutura teórica que produz um objeto (teórico) para reproduzir o objeto real na perspectiva da totalidade. Eis por que a teoria social moderna (indissoluvelmente ligada às formas econômico-sociais engendradas pelo modo de produção capitalista, quer pela própria possibilidade da sua constituição, quer pelos seus objetos científicos) não se instaura como somatório enciclopédico de saberes autônomos (história, economia, política, etc.). Contrariamente, é uma estrutura teórica unitariamente articulada sob a perspectiva da categoria fundamental da realidade social, a totalidade. E a exigência da totalidade não é posta como um simples imperativo metodológico: resulta, precisamente, das investigações histórico-concretas que Marx realizou, focando as formações econômico-sociais capitalistas.

A teoria social que a obra de Marx inaugura, por isto mesmo, implementa investigações e pesquisas sobre níveis distintos e específicos (econômico, político, social, etc.) da totalidade social - investigações e pesquisas elas mesmas levadas a cabo pelo ponto de vista da totalidade -, mas se organiza a partir da elaboração destas pesquisas e investigações de acordo com a determinação macroscópica posta pela concepção de totalidade. Só assim lhe é possível desvelar a ontologia do ser social, isto é: os modos de ser e reproduzir-se de uma sociedade determinada. Visto o primado ontológico da economia, a crítica da economia política aparece, pois, como 
o componente nuclear da teoria social de Marx (PAULO NETTO, 1985, p. $32)$.

Em 1987, Antonio Joaquim Severino prefaciava a publicação da Dissertação de Mestrado de Nelson Carvalho Marcellino afirmando que a influência da tradição metafísica clássica e da revolução pedagógica iluminista na formação da educação brasileira havia ressaltado a educação da e pela racionalidade e que sob a influência desta dupla tradição da pedagogia ocidental, a educação brasileira desenvolvera-se sob a orientação de um humanismo pedagógico fundado na afirmação da racionalidade como referência básica. Por esta razão, os demais aspectos da manifestação do existir humano não ocupam lugar de importância nas preocupações pedagógicas (SEVERINO In MARCELLINO, 1987, p. 912).

Este contexto era exposto com a finalidade de

[...] saudar com entusiasmo a contribuição do presente trabalho de Nelson Marcellino, ao tomar como tema de seu esforço de reflexão filosófica o lazer, enquanto elemento pedagógico de significação, ao propor assim alguns elementos para uma pedagogia da animação, pleiteando pelo reconhecimento da relação lazer-escola-processo educativo. Trata-se da incorporação do lazer na educação para o movimento da vida, mediante a criação de um ânimo, a provocação de estímulos, a cobrança da esperança, longe de uma simples representação de uma civilização do lazer que fosse apenas uma compensação da sociedade racionalista e produtivista dominada pela exploração do trabalho, onde o lazer tem sido visto tão somente num sentido funcionalista.

O esforço dessa proposta de recuperação pedagógica do lazer, vai no sentido de considerá-lo como uma força positiva, autêntica e autônoma, válida de per si, de encará-lo numa perspectiva de mudança, "relacionada a todo um processo amplo de educação, que considere as relações entre as possibilidades da escola e as potencialidades educativas do lazer, não como a 'redenção' de uma situação social injusta, mas como canal possível para busca da transformação aqui $\mathrm{e}$ agora" (SEVERINO In MARCELLINO, 1987, p. 9-12).

Severino estava apresentando o projeto que Marcellino divulgaria em duas de suas obras Lazer e Educação (1987) e Pedagogia da Animação (1990b) tendo como eixo central a formulação de uma alternativa pedagógica - a pedagogia da animação (MARCELLINO, 1987, p. 13, p. 142) - que viabilize a construção coletiva de uma nova escola, ligada à construção de uma nova sociedade (MARCELLINO, 1990b, p. 18). Afirmando que as diversas abordagens da educação entre nós, valorizam, antes de tudo, o trabalho como expressão humana, o autor vai defender a consideração das possibilidades do lazer como campo de intervenção pedagógica (MARCELLINO, 1987, p. 54-55) e de construção de contra hegemonia (MARCELLINO, 1987, p. 63-64), defendendo, ainda, a educação para o lazer com uma tarefa da escola (MARCELLINO, 1987, p. 75).

No processo de defesa deste projeto observava-se a negação do pensamento de Marx e de parte do marxismo, apoiada sobre a tese de que estes realizam o elogio do trabalho. Esta posição é perceptível em Lazer e Humanização (1983b, em 20048 ed.), em Lazer e Educação (1987, em 2004, 12 ed.), em Pedagogia da Animação (1990a, em 200712 ed.) e em Perspectivas para o lazer: mercadoria ou sinal de utopia (1992, em 2005, 12 ed.), cujas passagens são apresentadas sucessivamente a seguir: 
As críticas ao lazer são dirigidas também pelos marxistas. Muito embora os pensadores dessa linha estejam divididos em duas correntes, uma privilegiando o trabalho e outra o tempo fora do trabalho para a realização humana, uma vez que em Marx se encontram textos dos dois gêneros, predomina com muito peso a primeira corrente (MARCELLINO, 1983, p. 23.).

Embora o que se verifique atualmente seja a impossibilidade de referência ao marxismo como um pensamento unitário, pelas várias correntes que a denominação abriga, é certo que, em quase todas elas, ocorre a exaltação do trabalho. Seja como for, ironicamente, é o genro de Marx, Paul Lafargue, quem corajosamente elabora uma das primeiras sistematizações defendendo o lazer dos operários, em fins do século XIX, opondo-se não somente à mitificação do trabalho, como cerceamento da vida do trabalhador, mas também ao usufruto dos efeitos da exploração, pelos dominantes, também cerceados na sua vida em virtude das obrigações impostas pelo consumo. (MARCELLINO, 1987, p. 23).

Embora não exista um consenso entre os vários autores que se dedicam ao estudo do assunto, pelo menos a maioria deles concorda que é justamente esse período do início da consolidação da industrialização/urbanização, que marca, com contornos bastante nítidos, os campos das obrigações sociais, notadamente as profissionais - o trabalho - e do lazer (Marcellino 1983, 20-21). A partir dessa ruptura trabalho/lazer (Mills, 1969, 265-256), verifica-se uma variação no entendimento do significado do elemento lúdico da cultura nas sociedades urbano-industriais, que tem provocado polêmica entre os estudiosos do tema.

A base de toda essa polêmica, segundo meu entendimento, parece estar na valorização unilateral das diversas esferas de atuação humana. Na maioria das vezes, dá-se o confronto de posturas baseadas nas potencialidades do trabalho, sobretudo derivadas de uma interpretação de inspiração "marxista" (Marcellino 1983, 23; 1983, 23-24), ou do lazer, marcadas por um modelo "funcionalista" (Marcellino 1983, 26-29; 1987, 35-40). [...] Creio que estas posturas baseiam-se em possibilidades abertas de uma perspectiva ideal, e desse prisma deve-se considerar que as mesmas potencialidades que se oferecem ao trabalho, também poderão ser verificadas no lazer, entendidos ambos como campos de ação humana que busca satisfazer "necessidades". Assim, a análise em separado dos dois campos em si mesmos, e desvinculados do contexto social mais amplo, não pode ultrapassar o nível das possibilidades isoladas (MARCELLINO, 1990, p. 30-31).

A valorização unilateral da esfera do lazer feita por alguns autores vem provocando confronto com outras posturas também unilaterais. Na maioria das vezes esses confrontos ocorrem entre posturas derivadas de uma interpretação do trabalho de inspiração "marxista" e do lazer marcadas por um modelo "funcionalista". Entre essas últimas há os que distinguem sinais característicos de uma futura "civilização do lazer" do lazer que já estaria em gestação (Dumazedier, 1973; 1977, 45-52). Creio que essas posturas baseiam-se em possibilidades abertas de uma perspectiva ideal, e desse prisma se deve considerar que as mesmas potencialidades que se oferecem ao trabalho também poderão ser verificadas no lazer, entendidos ambos como campos de ação humana que buscam satisfazer necessidades. Assim, a análise em separado dos dois campos em si mesmos, e desvinculados do contexto social mais amplo, não pode ultrapassar o nível das possibilidades isoladas (MARCELLINO, 1992, p. 185). 
Do ponto de vista da investigação radical e rigorosa quanto à apropriação da obra de Marx e Engels para a compreensão da problemática do lazer, estas referências presentes em Marcellino seriam certamente desprezíveis - em virtude da evidente fragilidade na abordagem da categoria trabalho e na referência à obra de Marx e dos marxistas - não fossem três fatos bastante curiosos: (1) ter sido pronunciada pelo mais bem sucedido teórico do lazer no Brasil, considerando-se a recepção de seus trabalhos pelo mercado editorial; (2) ter sido pronunciada pelo autor que afirma apoiar-se em Gramsci para produzir uma proposta contra-hegemônica; (3) ser uma afirmação recorrente entre estudiosos do lazer de diferentes orientações teóricas.

Se tomamos a produção de Marcellino como ponto de partida para destacar a polêmica disseminação de posições acerca do pensamento de Marx e Engels (frequentemente atribuído exclusivamente a Marx) no âmbito dos estudos do lazer, é porque foi nesta obra que despertamos para o problema. No entanto, apesar de considerarmos urgente a revisão da produção deste autor enquanto um dos pilares dos estudos do lazer no Brasil, não foi esta a tarefa da pesquisa aqui relatada, mas a busca de explicações para a questão como estes estudos do lazer apropriam a obra matriz do marxismo, quais as motivações desta apropriação e qual o contexto que a explica.

Em determinado instante o processo de investigação evidenciou a impossibilidade de compreensão desta apropriação sem um amplo levantamento dos estudos do lazer no Brasil, na medida em que se fazia necessário reconhecer quando esta produção começa a acontecer no país; o que a estava motivando; quais as temáticas e problemáticas que privilegiava e por quê; quais os grandes debates que a orientam. Tratava-se de uma incursão histórica que procurava compreender a relação entre a produção do conhecimento referente aos estudos do lazer e a realidade brasileira. A pesquisa manteve a mesma questão que Marx e Engels se impuseram ao escrever A Ideologia Alemã entre 1845 e 1846, quando os autores esboçaram os pressupostos que orientaram a crítica radical e rigorosa à produção do conhecimento que imperou na Alemanha: a filosofia alemã, de matriz hegeliana, ficticiamente "revolucionada" pelos novos hegelianos e pelo materialismo de Feuerbach.

Os pressupostos da Concepção Materialista e Dialética da História orientaram as considerações que foram feitas no estudo. Neste contexto teórico, perguntar sobre a relação entre a produção do conhecimento referente aos estudos do lazer e a realidade brasileira, foi perguntar quais as bases materiais que sustentam, que estruturam a produção das ideias referentes ao tempo livre no Brasil? Como os brasileiros, no processo de produção e reprodução de sua existência, se veem obrigados a teorizar a prática do lazer?

A investigação que envolveu o levantamento, a análise do estado da arte e a revisão crítica da produção com vistas a buscar explicações para a apropriação da obra de Marx e Engels pelos estudos do lazer no Brasil foi orientada pela concepção teórica defendida pelos autores de que a "produção de ideias, de representações e da consciência" está "em primeiro lugar direta e intimamente ligada à atividade material e ao comércio material dos homens" sendo "a linguagem da vida real” (MARX e ENGELS, 1974, p. 25). Dizem-nos:

[...] são sempre indivíduos determinados, com uma atividade produtiva que se desenrola de um determinado modo, que entram em relações sociais e políticas determinadas. É necessário que, em cada caso particular, a observação empírica mostre nos factos, e sem qualquer especulação ou mistificação, o elo existente entre a estrutura social e política e a produção. A estrutura social e o Estado resultam constantemente do processo vital de indivíduos determinados; mas não resultam da aparência que estes indivíduos possam ter perante si mesmos ou perante outros e sim daquilo 
que são na realidade, isto é, tal como trabalham e produzem materialmente. Resultam portanto da forma como atuam partindo de bases, condições e limites materiais determinados e independentes de sua vontade.

A produção de ideias, de representações e da consciência está em primeiro lugar direta e intimamente ligada à atividade material e ao comércio material dos homens; é a linguagem da vida real. As representações, o pensamento, o comércio intelectual dos homens surge aqui como emanação direta do seu comportamento material. O mesmo acontece com a produção intelectual quando esta se apresenta na linguagem das leis, política, moral, religião, metafísica, etc., de um povo. São os homens que produzem as suas representações, as suas ideias, etc., mas os homens reais, atuantes e tais como foram condicionados por um determinado desenvolvimento das suas forças produtivas e do modo de relações que lhe corresponde, incluindo até as formas mais amplas que estas possam tomar. A consciência nunca pode ser mais do que os ser consciente; e o Ser dos homens é o seu processo de vida real. E se em toda a ideologia os homens e as suas relações nos surgem invertidos, tal como acontece numa câmara obscura, isto é apenas o resultado do seu processo de vida histórico, do mesmo modo que a imagem invertida dos objetos se forma na retina é uma consequência do seu processo de vida diretamente físico (MARX e ENGELS, 1974, p. 4-27).

Trata-se de, superando as abordagens idealistas, compreender as condições nas quais os homens reais, estão produzindo as suas representações, as suas ideias. Trata-se de procurar explicações para a produção dos estudos do lazer no Brasil no modo de produção e reprodução da existência, materializado no estágio de desenvolvimento das forças produtivas e nas relações de produção que lhe correspondem. Trata-se, em última instância, da tentativa de compreensão do movimento da produção do conhecimento referente aos estudos do lazer no Brasil no movimento mais amplo do modo de produção baseado no capital monopolista e imperialista que empurra todo o mundo subordinando-o à suas injunções. Um movimento marcado por conflitos violentos de interesses entre classes de homens que ocupam posições diametralmente opostas. Trata-se de compreender as repercussões e as características destes conflitos no Brasil e, em última instância, de buscar as explicações e conexões entre este movimento mais amplo e a produção do conhecimento referente aos estudos do lazer.

O esforço de sistematização da produção do conhecimento referente aos estudos do lazer buscou a compreensão do que estes estudos representam como fragmentos de uma história mais ampla: a história das lutas de classe no Brasil no século XX. A história da burguesia brasileira tentando alinhar-se aos interesses hegemônicos internacionais, e, nesta direção, seus esforços para conformar as demais classes em um grande pacto no qual seus interesses específicos de classe hegemônica vão aparecer como os interesses de todos os brasileiros. Dizem-nos Marx e Engels:

[...] cada nova classe no poder é obrigada, quando mais não seja para atingir os seus fins, a representar o seu interesse como sendo o interesse comum a todos os membros da sociedade ou, exprimindo a coisa no plano das ideias, obrigada a dar aos seus pensamentos a forma da universalidade, de os representar como sendo os únicos razoáveis, os únicos verdadeiramente válidos. Do simples fato de ela se defrontar com uma outra classe, a classe revolucionária surge-nos primeiramente não como classe mas como representante da sociedade inteira, como toda a massa da 
sociedade em choque com a única classe dominante. Isto é possível porque, no início, o seu interesse está ainda intimamente ligado ao interesse comum de todas as outras classes não dominantes e porque, sob a pressão do estado de coisas anteriores, este interesse ainda não se pôde desenvolver como interesse particular de uma classe particular. Por este fato, a vitória dessa classe é útil também a muitos indivíduos das outras classes que não conseguem chegar ao poder; mas é-o unicamente na medida em que coloca os indivíduos em estado de poder chegar à classe dominante. [...].Daqui se depreende que o combate que é necessário efetuar contra a nova classe dirigente terá por fim negar as condições sociais anteriores de uma forma mais decisiva e mais radical do que aquela que fora empregue por todas as classes que antes detiveram o poder. (MARX e ENGELS, 1974, p. 57).

O estudo permitiu concluir que a deflagração dos estudos do lazer no Brasil foi o resultado de uma política claramente configurada, face às demandas decorrentes da organização da burguesia (principalmente industrial e comercial, sem excluir a agrícola) que precisava controlar e impedir a organização da classe operária no Brasil. Os estudos do lazer expressam os conflitos de classe típicos do modo de produção da existência capitalista, em sua fase monopolista e imperialista, e os princípios que orientam estes estudos, conformam-se como leis que pretendem identificar, caracterizar, delimitar e controlar o lazer, sendo "a expressão ideal das relações materiais dominantes concebidas sob a forma de ideias e, portanto, a expressão das relações que fazem de uma classe a classe dominante" (MARX e ENEGELS, 1974, p. 56).

Explica-se que os conflitos de classe na produção do conhecimento referente aos estudos do lazer no Brasil são tamanhos, a ponto de fazer-se necessário negar categoricamente a contribuição da obra de Marx e Engels para a compreensão da problemática do lazer, compondo-se como um bloco ideologicamente configurado que visa efetivamente ao obscurecimento dos conflitos de classes de interesses irreconciliáveis: os interesses da classe trabalhadora e os interesses da classe que explora a classe trabalhadora, a classe dos capitalistas. A nosso ver, este esforço de exclusão da obra de Marx, Engels (e de parte do marxismo) dos referenciais que poderiam contribuir para a explicação da problemática do lazer durante boa parte do século $\mathrm{XX}$, não ocorreu por acaso, do mesmo modo que sua retomada no final deste século foi expressão da constatação de que o esforço de compreensão radical e rigorosa da problemática do lazer depende da apropriação destes autores e referenciais.

Ao mesmo tempo em que se constatou o modo como a obra de Marx e Engels foi apropriada pelos estudos do lazer (PEIXOTO, 2007a), procurou-se na obra destes gigantes conhecimento de ponta e totalmente atual no que toca à interpretação do modo capitalista de produção e reprodução da existência em vigor nos últimos 200 anos - as que permitirão explicar a prática, as políticas, a formação e a produção do conhecimento referente aos estudos do lazer tal como vão se desenvolver no Brasil (PEIXOTO, 2007a; PEIXOTO, 2010a; PEIXOTO, 2011).

Trata-se de apontar a centralidade da obra de Marx e Engels para a problemática do lazer, quando, então, explicamos as razões pelas quais é impossível discutir com radicalidade e rigor esta problemática, sem uma adequada revisão da crítica de Marx e Engels às abordagens idealistas dos problemas humanos e ao modo capitalista de produção e reprodução da existência no qual inscrevem-se hoje todas as práticas humanas. 


\section{Conclusões}

Ao buscar explicações para a relação entre a produção do conhecimento referente aos estudos do lazer no Brasil e a realidade brasileira, tem-se em mente que a produção de ideias, de representações e da consciência está em primeiro lugar direta e intimamente ligada à atividade material e ao comércio material dos homens, configurando-se naquilo que Marx e Engels (1974, p. 25) vão chamar de linguagem da vida real:

As representações, o pensamento, o comércio intelectual dos homens surge aqui como emanação direta do seu comportamento material. $\mathrm{O}$ mesmo acontece com a produção intelectual quando esta se apresenta na linguagem das leis, política, moral, religião, metafísica, etc., de um povo. São os homens que produzem as suas representações, as suas ideias, etc., mas os homens reais, atuantes e tais como foram condicionados por um determinado desenvolvimento das suas forças produtivas e do modo de relações que lhe corresponde, incluindo até as formas mais amplas que estas possam tomar. A consciência nunca pode ser mais que o Ser consciente; e os Ser dos homens é o seu processo da vida real. [...].

Contrariamente da filosofia alemã, que desce do céu para a terra, aqui, parte-se da terra para atingir o céu. Isto significa que não se parte daquilo que os homens dizem, imaginam e pensam nem daquilo que são nas palavras, no pensamento, na imaginação e na representação de outrem para chegar aos homens em carne e osso; parte-se dos homens, da sua atividade real. É a partir do seu processo de vida real que se representa o desenvolvimento dos reflexos e das repercussões ideológicas deste processo vital. [...]. Não é a consciência que determina a vida, mas sim a vida que determina a consciência (MARX e ENGELS, 1974, p. 25-26).

Sob esta orientação teórica, Marx e Engels fizeram a crítica à ideologia alemã, na forma do pensamento jovem hegeliano. A premissa fundamental que orientou a crítica ao pensamento jovem hegeliano foi que a produção das ideias deve ser procurada não nos indivíduos isolados e fixos, mas no seu processo de desenvolvimento real, em condições determinadas, desenvolvimento este que é visível empiricamente (MARX e ENGELS, 1974, p. 26). Dependentes eternos da atividade vital que lhes permite a produção da vida (o trabalho), o estudo das ideologias deve perseguir o desenvolvimento histórico dos homens no processo contínuo de produção de sua existência. É em cada modo de produção concretamente situado (escravagista, feudal, capitalista), em suas diferentes fases, que devem ser buscadas as explicações para as ideologias produzidas naquele contexto histórico. É determinante, na tentativa de apreensão do processo de desenvolvimento real dos homens, observar o desenvolvimento das forças produtivas e suas correspondentes relações de produção. É apenas sob esta perspectiva que a história deixa de ser uma coleção de fatos sem vida, expressando o movimento material contraditório e dialético que leva à produção das ideias (MARX e ENGELS, 1974, p. 25-27). No Prefácio à Contribuição à crítica da economia política (1977), Marx dirá:

Nas minhas pesquisas cheguei à conclusão de que as relações jurídicas assim como as formas do Estado - não podem ser compreendidas por si mesmas, nem pela dita evolução geral do espírito humano, inserindo-se pelo contrário nas condições materiais de existência de que Hegel, à semelhança dos ingleses e franceses do século XVIII, compreende o conjunto pela designação de "sociedade civil"; por seu lado, a anatomia da sociedade civil deve ser procurada na economia política. [...] na produção 
social da sua existência, os homens estabelecem relações determinadas, necessárias, independentes da sua vontade, relações de produção que correspondem a um determinado grau de desenvolvimento das forças produtivas materiais. O conjunto destas relações de produção constitui a estrutura econômica da sociedade, a base concreta sobre a qual se eleva uma superestrutura jurídica e política e a qual correspondem determinadas formas de consciência social. $O$ modo de produção da vida material condiciona o desenvolvimento da vida social, política e intelectual em geral. Não é a consciência dos homens que determina o seu ser; é o seu ser social que, inversamente, determina a sua consciência. Em certo estágio de desenvolvimento, as forças produtivas materiais da sociedade entram em contradição com as relações de produção existentes ou, o que é a sua expressão jurídica, com as relações de propriedade no seio das quais se tinham movido até então. De formas de desenvolvimento das forças produtivas, estas relações transformam-se no seu entrave. Surge então uma época de revolução social. A transformação da base econômica altera, mais ou menos rapidamente, toda a imensa superestrutura. Ao considerar tais alterações é necessário sempre distinguir entre a alteração material - que se pode comprovar de maneira cientificamente rigorosa das condições econômicas de produção, e as formas jurídicas, políticas, religiosas, artísticas ou filosóficas, em resumo, as formas ideológicas pelas quais os homens tomam consciência deste conflito, levando-o às suas últimas consequências. Assim como não se julga um indivíduo pela ideia que ele faz de si próprio, não se poderá julgar uma tal época de transformação pela mesma consciência de si; é preciso, pelo contrário, explicar esta consciência pelas contradições da vida material, pelo conflito que existe entre as forças produtivas sociais $e$ as relações de produção (MARX, 1977, p. 24-25).

Sob estas premissas propostas por Marx e Engels, buscamos apreender o movimento material, real, contraditório e dialético que leva à produção do conhecimento referente aos estudos do lazer no Brasil. Concretamente, esboçados os traços gerais dos ciclos da produção do conhecimento que mapeamos (PEIXOTO, 2007a; PEIXOTO e PEREIRA, 2010b) trata-se de explicar no próprio desenvolvimento das forças produtivas e das relações de produção no Brasil, o conflito de interesses que vai determinar a produção de teorias norteadoras da prática do lazer. Mas não falamos de qualquer prática do lazer. Tratamos das teorias que vão propor orientações para a prática do lazer da classe trabalhadora. Falamos, concretamente, das bases reais que vão permitir a produção de teorias para a ocupação do tempo livre da classe trabalhadora brasileira.

O processo de análise da produção do conhecimento referente aos estudos do lazer no Brasil em busca da identificação da forma como a obra de Marx e Engels foi apropriada apropriada pelos estudiosos do lazer brasileiros permitiu afirmar a existência de um projeto claramente configurado de ocupação do problemático tempo livre gerado com a redução progressiva da jornada de trabalho nas décadas inicias do século XX que culmina com a CLT. Este projeto de ocupação do tempo livre configurou-se em diversas áreas do conhecimento, em um processo de busca de precisão do que é e do que não é adequado para o preenchimento do tempo livre, que resultou em delimitação dos valores a serem disseminados, de propostas de práticas mais adequadas à conquista destes valores e de políticas de implementação destas propostas (PEIXOTO, 2007a; PEIXOTO e PEREIRA, 2010b).

De caráter funcionalista, este projeto visava a contenção do processo de organização da classe trabalhadora no Brasil, e, especialmente, o controle do avanço das ideias 
comunistas no país. Obviamente, este projeto evitou as teorias que explicitam os conflitos de classe e, entre estas, as obras de Marx e Engels, ora ignorando esta produção; ora agregando-a de forma fragmentada e conforme a conveniência; ora afirmando não ser esta obra adequada para a compreensão da problemática do lazer por tratar-se de obra que providencia o elogio do trabalho, algo inadmissível nos tempos da prometida sociedade do lazer (PEIXOTO, 2007a). Compreender esta produção do conhecimento referente aos estudos do lazer no Brasil e o contexto histórico no qual se processa, em busca de explicar as motivações a ela subjacentes foi o alvo central deste estudo. Tal movimento foi realizado orientado pelo entendimento de que a explicação da produção de ideias, enquanto um determinado estágio de consciência sobre a realidade objetiva, só é possível pela explicação das contradições postas na vida material, no próprio conflito existente entre as forças produtivas e as relações de produção (MARX e ENGELS, 1974, p. 4-27, p. MARX, 1977, p. 25).

\section{Referências}

ALBUQUERQUE, Joelma Oliveira. A produção de pesquisas em educação física, esporte e lazer com a temática escola no nordeste brasileiro [1982-2004]: mediações e possibilidades da educação para além do capital. 2007. Dissertação. (Mestrado em Educação). Programa de Pós-Graduação em Educação. Faculdade de Educação. Universidade Federal da Bahia, Salvador. 2007.

ÁVILA, Astrid Baecker. A pós-graduação em educação física e as tendências na produção do conhecimento: o debate entre realismo e anti-realismo. 2008. Tese (Doutorado). Programa de Pós-Graduação em Educação. Universidade Federal de Santa Catarina, Florianópolis. 2008.

GAMBOA, S. A. S. Epistemologia da pesquisa em educação: estruturas lógicas e tendências metodológicas. 1987. Tese (Doutorado). Programa de Pós-Graduação em Educação. Universidades Estadual de Campinas, Campinas, 1987.

GAMBOA, S. A. S. Epistemologia da pesquisa em educação. Campinas: Práxis, 1986.

GUILHERME, V. S. ; MANCONI, A. P. ; PEIXOTO, E. M. de M. Levantamento, catalogação e análise da produção do Conhecimento referente à relação trabalho x lazer nos estudos do lazer no Brasil (1980-2000). Estudos do Trabalho, v. III, p. 1-19, 2010.

LOMBARDI, J. C. Marxismo e história da educação: algumas reflexões sobre a historiografia educacional brasileira recente. Tese (Doutorado) - Faculdade de Educação, Universidade Estadual de Campinas (UNICAMP), Campinas. 1993.

LOMBARDI, J. C. Reflexões sobre educação e ensino na obra de Marx e Engels. (Tese de Livre Docência) PPG em EDUCAÇÂA. UNICAMP, Faculdade de Educação. Outubro, 2009.

MARCELLINO, N. C. Lazer e educação. Campinas: Papirus, 1987.

MARCELLINO, N. C. Lazer e humanização. Campinas: Papirus, 1983 b.

MARCELliNO, N. C. Pedagogia da animação. Campinas: Papirus, $1990 \mathrm{~b}$.

MARX, K. Contribuição à crítica da economia política. São Paulo: Martins Fontes, 1977.

MARX, K.; ENGELS, F. A ideologia alemã. Porto/ São Paulo: Editorial Presença/Livraria Martins Fontes, 1974. $2 \mathrm{v}$.

MARX, K.; ENGELS, F. A sagrada família. São Paulo: Boitempo, 2003.

MARX, Karl e ENGELS, Friedrich. A sagrada família: A crítica da crítica crítica: contra Bruno Bauer e consortes. São Paulo: Boitempo Editorial, 2003. 280 p.

MARX, Karl e ENGELS, Friedrich. Obras Escolhidas. São Paulo: Alfa Ômega, 1980c. 3 $\mathrm{v}$. 
MARX, Karl; ENGELS, Friedrich. Manifesto comunista. São Paulo : Boitempo, 1998. MARX, Karl. Contribuição à crítica da economia política. São Paulo: Martins Fontes, 1977.

MARX, Karl. Contribuição à crítica da economia política. São Paulo: Expressão Popular, 2008.

MARX, Karl. Crítica da filosofia do direito de Hegel. 1. ed. São Paulo: Boitempo, 2005. MARX, Karl. Manuscritos econômico-filosóficos. São Paulo: Boitempo, 2004.

MARX, Karl. O Capital : crítica da economia política - o processo de produção de capital. Livro 1. Volume I. Rio de Janeiro : Bertrand Brasil, 1989a.

MARX, Karl. O Capital : crítica da economia política - o processo de produção de capital. 12 ed. Livro 1. Volume II. Rio de Janeiro : Bertrand Brasil, 1989b.

PAULO NETTO, J. Introdução. In: MARX, K. A miséria da filosofia. São Paulo: Expressão Popular, 2009.

PEIXOTO, E. M. de M. Estudos do lazer no Brasil: apropriação da obra de Marx e Engels. 2007a. Tese (Doutorado) - Educação. Faculdade de Educação, Universidade Estadual de Campinas. Campinas.

PEIXOTO, E. M. de M. Os estudos do lazer no Brasil e a apropriação da obra de Marx e Engels - Maria Isabel Leme Faleiros. Movimento (Porto Alegre), v. 13, p. 197-218, 2007b.

PEIXOTO, E. M. de M. Levantamento do estado da arte nos estudos do lazer: (Brasil) séculos XX e XXI - alguns apontamentos. Educação \& Sociedade (Impresso), v. 28, p. 561-586, 2007c.

PEIXOTO, E. M. de M. O desafio de explicar o lazer à luz do marxismo. Boletim Germinal: Grupo de Estudos e Pesquisas Marxismo, História, Tempo Livre e Educação (Londrina. Online), v. 4, p. 2-2, 2008a.

PEIXOTO, E. M. de M. Estudo da categoria modo de produção da existência na obra de Marx e Engels e suas implicações para a problemática do lazer (projeto 04927). Boletim Germinal, Grupo de Estudos e Pesquisas Marxismo, História, Tempo Livre e Educação (Londrina. Online), v. 2, p. 2-2, 2008 b.

PEIXOTO, E. M. de M. O serviço de recreação operária e o projeto de conformação da classe operária no Brasil. Pro-Posições (UNICAMP. Impresso), v. 19, p. 0103, 2008c.

PEIXOTO, E. M. de M. Os estudos do lazer no Brasil - apropriação da obra de Marx e Engels. Movimento (Porto Alegre), v. 13, p. 87-116, 2008d.

PEIXOTO, E. M. de M. Marx e Engels: superação do idealismo pela concepção materialista e dialética da história. Boletim Germinal: Grupo de Estudos e Pesquisas Marxismo, História, Tempo Livre e Educação (Londrina. Online), v. 5, p. 5-7, 2008e.

PEIXOTO, E. M. de M.; PEREIRA, M. F. R. ; LOMBARDI, José Claudinei ; FREITAS, F. M. C. Estudo da categoria modo de produção da existência na obra de Marx e Engels e suas implicações para a compreensão da problemática do lazer: relatório final do Projeto 04927. Motrivivência (Florianópolis), v. XXI, p. 352-374, 2009.

PEIXOTO, E. M. de M. Fundamentos marxistas: modo de produção como eixo para uma síntese em perspectiva histórica da relação Trabalho/Educação Física, Esportes e Lazer. Motrivivência (Florianópolis), v. XXII, p. 99-112, 2010a.

PEIXOTO, E. M. de M. ; PEREIRA, M. F. R. O primeiro ciclo dos estudos do lazer o Brasil. Movimento (UFRGS. Impresso), v. 16, p. 267-288, $2010 \mathrm{~b}$.

PEIXOTO, E. M. de M. Notas Introdutórias sobre a teoria e as categorias centrais para a pesquisa da problemática do lazer. Revista HISTEDBR On-line, v. Esp., p. 332-346, 2011. 
PEIXOTO, E. M. de M. Interdisciplinaridade e análise da produção científica: apontamentos a partir da concepção materialista e dialética da história. Filosofia e Educação, v. 5, p. 120-165-165, 2013 a.

PEIXOTO, E. M. de M. Marxismo, educação e emancipação humana. Germinal: Marxismo e Educação em Debate, v. 5, p. 5-28-28, 2013 b.

SÁ, K. O. de. Pressupostos ontológicos da produção do conhecimento do lazer no Brasil - 1972 a 2008: realidade e possibilidades na pós-graduação e graduação em educação física. Tese (Doutorado). Programa de Pós-Graduação em Educação. FACED/UFBA. 2007.

SAVIANI, D. A filosofia na formação do educador. In: SAVIANI, D. Educação: do senso comum à consciência filosófica. Campinas: Autores Associados, 2007. P. 11-30.

SILVA, R. V. S. Mestrados em educação física no Brasil: pesquisando suas pesquisas. 1990. Dissertação (Mestrado) - Educação Física. Universidade Federal de Santa Maria, Santa Maria, 1990.

SILVA, R. V. S. Pesquisa em Educação física: determinações históricas e implicações metodológicas. 1997. Tese (Doutorado em Educação) - Faculdade de Educação, Universidade Estadual de Campinas, Campinas, 1997.

TRIVINUS, A. N. S. Questões preliminares básicas. In: TRIVINUS, A. N. S. Introdução à pesquisa em ciências sociais. São Paulo: Atlas, 2011.

Notas

' Texto reformulado a partir do texto apresentado no painel intitulado Crítica da produção do conhecimento à luz das determinantes do modo de produção: contribuição ao debate da formação de professores em pedagogia e educação do campo durante o XVI ENDIPE - Encontro Nacional de Didática e Práticas de Ensino, realizado na Universidade Estadual de Campinas (UNICAMP) no ano de 2012.

ii PPGE - FACED - UFBA

iii Produção do conhecimento e prática social ausentes de "coerência entre os suportes teóricos", caracterizada pela "mistura de correntes de pensamento", por uso de "citações avulses for a de contexto", denotando-se ai "informação indisciplinada" e "farqueza intelectual" (TRIVINUS, 2011, p. 15).

${ }^{i v} \mathrm{O}$ estudo cronológico da crítica que Marx e Engels fizeram (1) ao idealismo alemão - na forma da crítica ao idealismo especulativo produzido por Georg Wilhelm Friedrich Hegel (1770-1831) e pelos jovens hegelianos ou hegelianos de esquerda, Bruno Bauer (1809-1883), Max Stirner (1806-1856), Ludwig Fuerbach (18041872), Moses Hess (1812-1865) - sistematizada nas obras Crítica da filosofia do direito de Hegel (1843), Introdução à Crítica da filosofia do direito de Hegel (1844), A questão judaica (1844), A sagrada família (1845) e A ideologia alemã (1845-1846); (2) à economia política inglesa - sistematizada nas obras Esboço de uma crítica da economia política (1844); Miséria da filosofia (1847); Contribuição à crítica da economia política (1859); Salário, preço e lucro (1865); O capital (1867-1879); A origem da família, da propriedade privada e do Estado (1884); (3) e ao socialismo utópico francês - sistematizada nas obras A ideologia alemã (1845-1846); Princípios do comunismo (1847); Manifesto Comunista (1848); Anti-Duhring (1877-1878); Do socialismo utópico aos socialismo científico (1880); nos permitiu reconhecer os pressupostos teóricos para a crítica da abordagem idealista e eclética que os estudiosos do lazer vinham fazendo da problemática do lazer; assim como nos permitiu apropriar consistente base teórica para compreender o objeto lazer e a produção do conhecimento sobre o objeto, os estudos do lazer, reconhecendo as formulações mais avançadas para a explicação da problemática. 